\title{
ALUNOS COM NECESSIDADES \\ EDUCATIVAS ESPECIAIS: 0 \\ OLHAR DA AVALIAÇÃO \\ EXTERNA DE ESCOLAS
}

\author{
ALUMNOS CON NECESIDADES EDUCATIVAS \\ ESPECIALES: LA PERCEPCIÓN DE LA EVALUACIÓN \\ EXTERIOR DE ESCUELAS
}

\section{STUDENTS WITH SPECIAL NEEDS EDUCATION: THE PERCEPTION OFTHE EXTERNAL ASSESMENT OF SCHOOLS}

Raquel Batista de OLIVEIRA ${ }^{1}$

Maria Piedade VAZ-REBELO

Maria da Graça Amaro BIDARRA ${ }^{3}$

\section{Resumo}

Este artigo insere-se na temática da educação inclusiva de alunos com Necessidades Educativas Especiais (NEE) em turmas regulares do ensino público em Portugal, tendo como base a atual legislação sobre a inclusão de alunos com NEE, mais concretamente o Decreto 3/2008 e o quadro de referência da Avaliação Externa das Escolas (AEE) levada a cabo pela IGEC, procura-se conhecer as práticas de diferenciação e apoios que se desenrolam nas escolas. Dado que estas práticas não são objeto de classificação no âmbito do segundo ciclo avaliativo que se iniciou em 2011/2012,

\footnotetext{
${ }^{1}$ Doutoranda em Ciências da Educação pela Faculdade de Psicologia e Ciências da Educação da Universidade de Coimbra- Endereço: Rua do Colégio Novo - cep: 3000-115 - Coimbra Portugal.

${ }^{2}$ Professora auxiliar da Faculdade de Psicologia e Ciências da Educação da Universidade de Coimbra. Endereço: Rua do Colégio Novo - cep: 3000-115 Coimbra Portugal.

${ }^{3}$ Associada da Faculdade de Psicologia e Ciências da Educação da Universidade de Coimbra. Endereço: Rua do Colégio Novo - cep: 3000-115 - Coimbra Portugal.
} 
interessa proceder ao seu mapeamento nos campos de análise que integram a Prestação do Serviço Educativo, bem como nos Pontos fortes e Áreas de melhoria das escolas. Para efeito, recorre-se à análise de conteúdo dos relatórios da Zona Centro de Portugal Continental, tomando como corpus o domínio Prestação do Serviço Educativo e as asserçôes relativas aos Pontos fortes e Áreas de melhoria. Os resultados evidenciam que as práticas de diferenciação e apoios são mais frequentes nos Pontos fortes do que nas Áreas de melhoria das escolas, e que são mais referidas nas Práticas de ensino comparativamente ao Planeamento e articulação e Monitorização e avaliação das aprendizagens.

Palavras-chave: Inclusão; Avaliação Externa das Escolas. Diferenciação pedagógica. Apoios educativos.

\section{Resumen}

Este artículo se concentra en la temática de educación inclusiva de alumnos con Necesidades Educativas Especiales (NEE) en grupos regulares de la enseñanza básica en Portugal, teniendo como base la actual legislación sobre la inclusión de alumnos con $N E E$, en concreto el Decreto 3/2008 y el cuadro de referencia de la Evaluación Externa de las Escuelas (AEE) realizado por GEIC busca conocer las prácticas de Discriminación y el Apoyo que tienen lugar en las escuelas. Dado que estas prácticas no son objeto de imputación en el segundo ciclo de evaluación que comenzó en 2011/2012, interesa realizar el mapeo en los campos del análisis que integran la Prestación de Servicios Educativos, así como los Puntos fuertes y Áreas de mejora escuelas. Con efecto, utilizamos la Análisis de contenido el Zona Centro de Portugal Continental, tomando como corpus el Dominio del Servicio prestación educativa y afirmaciones con respecto a los puntos fuertes y áreas de mejora. Los resultados evidencian que las prácticas de diferenciación y apoyo son más frecuentes en los Puntos fuertes de que en las Áreas de mejoría de las escuelas, y que son los más mencionados en las Prácticas Educativas en comparación con la Planificación y la Coordinación y el seguimiento y la Evaluación del Aprendizaje.

Palabras clave: Inclusión. Evaluación Externa de las Escuelas; Diferenciación pedagógica; Apoyos educativos. 


\section{Abstract}

The present article is part of the theme educational inclusion for Special Needs Education (SNE) students in regular classes in the public educational system in Portugal, taking as reference the current legislation regarding the inclusion of SNE students, specifically Decree 3/2008, and the External School Assessment (ESA), carried out by IGEC looking to know the discrimination practices and support that take place in schools. Since these practices are not assignment object in the second evaluation cycle that began in 2011/2012, interests undertake the its mapping in the fields of analysis that integrate the Provision of Educational Services as well as the Strengths and Improvement aspects schools. We make use of content analysis of the Center of Portugal Zone reports taking the corpus the domain Provision of Educational Services of the Center of Portugal Zone reports. The results make evident that the differentiation and support practices are more frequent in Strong aspects in school than Improvement aspects, which are most frequently mentioned in Educational Practices compared with the Planning and Coordination and Monitoring and Assessment of Learning.

Key words: Inclusion. External School Assessment. Pedagogical Differentiation. Educaional Support.

\section{INTRODUÇÃO}

O presente estudo tem como objetivo conhecer o olhar da Avaliação Externa de Escolas (AEE) sobre os alunos com Necessidades Educativas Especiais (NEE) e as práticas de diferenciação e apoios. Com efeito, defendendo-se uma escola inclusiva, importa perceber de que modo a AEE reporta estas mesmas práticas. Neste sentido, procedemos à contextualização do estudo, traçando a evolução no domínio legislativo no que se refere à educação especial e a evolução no quadro de referência da $\mathrm{AEE}$, desenvolvendo um estudo empírico de natureza documental, que tem por base os relatórios de AEE da Zona Centro de Portugal Continental, relativos ao ano de 2011/2012, cuja metodologia e resultados apresentamos nas respetivas secçóes deste artigo.

ALUNOS COM NECESSIDADES EDUCATIVAS ESPECIAIS: O OLHAR DA AVALIACCĀO EXTERNA DE ESCOLAS

tets

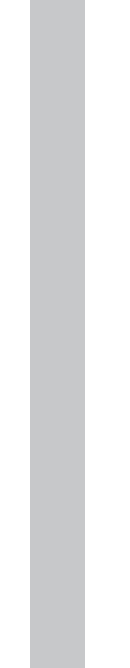


ENQUADRAMENTO LEGAL SOBRE A INCLUSÃO DE ALUNOS COM

\section{Necessidades Educativas Especiais}

$\mathrm{Na}$ atualidade parece consensual que educação inclusiva e educação especial constituem conceitos solidários, pois na realidade, como salienta Correia (2010), uma não sobrevive sem a outra. Vários autores têm contribuído para a identificação dos pressupostos da educação inclusiva, sendo de destacar, entre outros Niza (1996), Correia (1999, 2008, 2010) Leite (2011), Rodrigues (2001, 2003). A evolução dos conceitos relacionados com a educação especial, bem como as recomendaçóes emanadas de organismos internacionais, conduziram à elaboração de diplomas que traduzem novos olhares sobre os alunos com necessidades educativas especiais.

O conceito de "alunos com necessidades educativas especiais", baseado em critérios pedagógicos, foi introduzido pelo DL 319/91, substituindo a classificação em diferentes categorias de foro médico, e responsabilizando a escola regular pelos problemas dos alunos com deficiência ou com dificuldades de aprendizagem, agora concebida como umas "escola para todos". Este decreto "vem preencher uma lacuna há muito sentida, no âmbito da Educação Especial, atualizando, alargando e precisando o seu campo de acção" (CORREIA, 1999, p. 29). Teixeira (2008, p. 38) sustenta ainda que este decreto "[...] constituiu um marco decisivo na garantia do direito de frequência das escolas regulares por parte de muitos alunos que, até então, estavam a ser educados em ambientes segregados". No âmbito desta lei, em termos de medidas educativas, segundo o princípio do meio o menos restritivo possível, contam-se: equipamentos especiais de compensação, adaptaçôes materiais, adaptações curriculares, condiçóes especiais de matrícula, condiçôes especiais de frequência, condiçóes especiais de avaliação, adequação na organização de classes ou turmas, apoio pedagógico acrescido e ensino especial.

No âmbito dos avanços legislativos, em de 7 de Janeiro de 2008 entra em vigor o Decreto-Lei 3/2008 
que revoga o Decreto-Lei 319/91. Assim, aquele propóe princípios, valores, instrumentos necessários para garantia da qualidade da educação a todos os alunos no processo de ensino e aprendizagem, identificando as medidas e estruturas organizativas neste domínio (cf. OLIVEIRA, 2014). Tendo em vista as necessidades dos alunos com NEE de caráter permanente, este decreto vem viabilizar a adequação do processo educativo daqueles no âmbito das "atividades e participação num ou vários domínios da vida" (CAPUCHA, 2008, p. 11).

Este decreto especifica o público-alvo a ser atendido pelas medidas de apoio da educação especial, ou seja, estarão incluídos no acesso a estas medidas os alunos com NEE de caráter permanente, excluindo, deste modo, aqueles que não se enquadram nesta especificidade. Recentemente, foi publicada a Portaria no 275-A/2012, que regulou algumas medidas específicas da educação especial, tais como o Currículo Específico Individual (CEI) e o Programa Individual de Transição (PIT), como se adianta:

A presente portaria regula o ensino de alunos com currículo específico individual (CEI), em processo de transição para a vida pós-escolar, nos termos e para os efeitos conjugados dos artigos $14^{\circ}$ e $21^{\circ}$ do Decreto-Lei 3/2008, de 7 de janeiro, na sua redação atual [...]. (Ministério da Educação e Ciência de Portugal).

Este decreto tem levantado algumas controvérsias na comunidade educativa, sendo reconhecidas algumas potencialidades, mas igualmente algumas limitaçóes por diferentes autores. Referimo-nos ao público-alvo, ao uso da Classificação Internacional de Funcionalidade (CIF) para identificação do aluno que apresenta NEE (caráter permanente) e ao funcionamento das estruturas organizativas do ensino especial. No que concerne às limitaçóes deste decreto, Correia (2008) afirma que o mesmo retrocede, pois deixa de fora outros alunos que não se incluem nos critérios

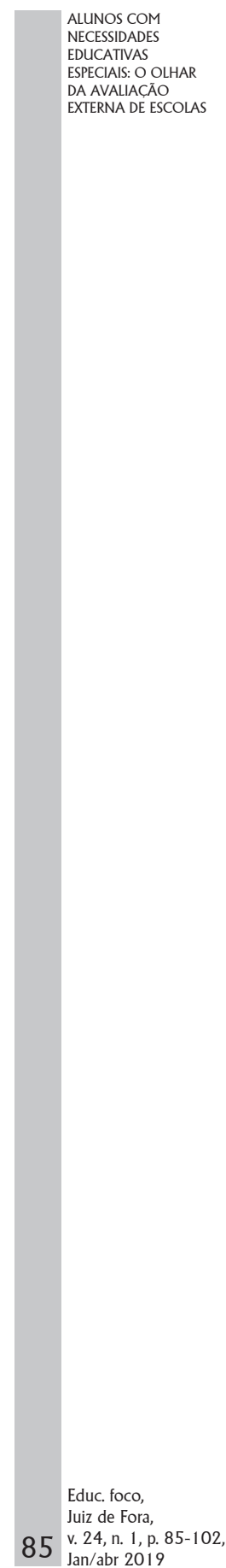

NECESSIDADES

A AVALIAÇĀO

XTERNA DE ESCOLAS

v. 24, n. 1, p. $85-102$ Jan/abr 2019 
da elegibilidade das NEEs de caráter permanente. Sobre isto, o mesmo autor refere:

Ao parecer limitar o atendimento às necessidades educativas especiais dos alunos surdos, cegos, com autismo e com multideficiência [...] está a discriminar a esmagadora maioria dos alunos com NEE permanentes [...] alunos com problemas intelectuais (deficiência mental), com dificuldade de aprendizagens específicas (por exemplo, dislexia, disgrafias, discalculias, dispraxias, dificuldades de aprendizagens não-verbais), com desordens por falta de atenção, com perturbaçóes emocionais e de comportamento graves e com problemas de comunicação (por exemplo, problemas específicos de linguagem). (CORREIA, 2008, p. 73).

No que diz respeito às Escolas de Referência voltadas aos alunos surdos, Correia (2008) considera que o DecretoLei não deixa claro se a educação bilingue destes alunos tem o propósito de uma educação inclusiva. Com efeito, afirma:

Fica-se sem saber se estes alunos se enquadram no espectro dos alunos com NEE permanentes, receptores de serviços de educação especial, ou se, pelo contrário fazem parte de uma comunidade, com línguas e culturas próprias, que deve beneficiar de uma educação bilingue (CORREIA, 2008, p. 72).

Sobre o uso da CIF para a elegibilidade dos alunos com NEEs de caráter permanente, Correia (2008) refere as suas limitaçóes no âmbito da inadequação das definiçóes clínicas e educativas, na incompletude do reconhecimento junto ao desempenho educativo e no uso prematuro da CIF para elegibilidade das NEEs.

Em opinião contrária, alguns autores defendem que o Decreto-lei 3/2008 contribuiu muito para o atendimento de qualidade aos alunos com NEE de caráter permanente (MCANANEY, 2007, cit. por CAPUCHA, 2008). Apontando 
Uma vez aceite o argumento a favor de uma abordagem biopsicossocial para o desenvolvimento de um sistema de educação inclusiva, resta a questão sobre qual o quadro conceptual que melhor reflecte os princípios e valores deste modelo e que pode fornecer um meio sistemático de fundamentar as necessidades, como os pontos fortes individuais e ambientais.

Nesta perspectiva, não existe quadro de referência mais apropriado e relevante do que a CIF. A CIF possui um conjunto de características que fazem dela um quadro de referência ideal para apoiar o desenvolvimento e implementaçáo de uma avaliação abrangente do processo de necessidades em educação. (MCANANEY, 2007, cit. por CAPUCHA, 2008, p. 92).

Além disso, o uso da CIF permite esclarecer os pais sobre a elegibilidade dos alunos, fundamenta o plano pedagógico e o desenvolvimento do currículo. Pinto (2012, p. 37) defende que o "Decreto-Lei n. ${ }^{\circ}$ 3/2008 apresenta uma verdadeira inovação, a utilização da comummente designada por CIF (OMS, 2003), uma classificação da Organização Mundial de Saúde [...]".

Com efeito, Capucha (2008) refere que o Decreto-Lei 3/2008 trouxe contribuiçôes no âmbito da vida pós-escolar para os alunos com NEE de caráter permanente (que possuem o CEI), pois três anos antes do término da escolaridade acrescenta ao PEI o PIT que tem por objetivo promover junto do aluno com NEE a sua capacitação para adquirir competências sociais no sentido de que este seja capaz de efetivar o seu projeto de vida. Consubstancialmente, conforme o decreto, acima citado, em seu art. $14^{\circ}$, este documento deve ser flexível respondendo adequadamente aos desejos, aspirações e competências do aluno, deve também clarificar e definir as etapas necessárias para o desenvolvimento das ações desde o início até a conclusão do percurso educativo.

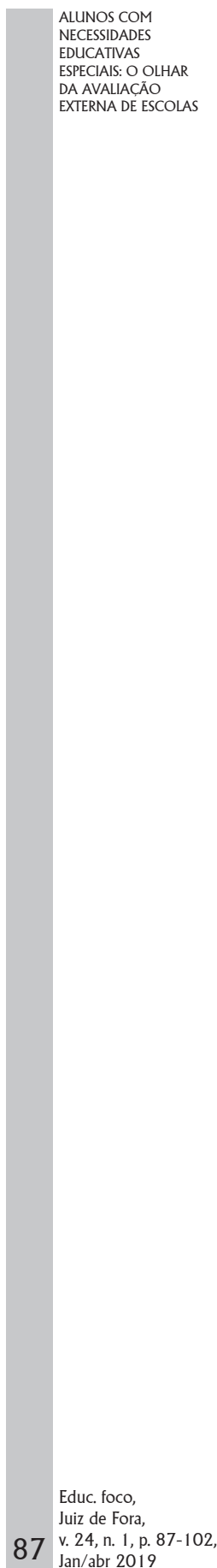




\section{As práticas inclusivas à luz da Avaliaçáo Externa de Escolas em Portugal}

Sabe-se que um dos pressupostos da inclusão de alunos com NEE nas escolas de ensino regular é a garantia de uma educação de qualidade para atender à diversidade de alunos através de respostas educativas adequadas e eficazes para estes. Com efeito, defendendo-se uma escola inclusiva, interessa conhecer de que modo as práticas de inclusão e as medidas de diferenciação e apoios têm sido consideradas no âmbito da avaliação institucional de escolas, sendo para isso relevante compreender o processo de AEE a decorrer em Portugal. Com efeito, tem vindo a assumir particular ênfase, nas últimas décadas, a avaliação de escolas, existindo um Programa Nacional de Avaliação Externa de Escolas (AEE), levada a cabo pela Inspeção Geral de Educação e Ciência, que se iniciou no ano de 2006, desencadeado pela Lei no 31/2002, de 20 de dezembro, o qual tem por objetivo avaliar a qualidade da educação nas instituiçóes de ensino não superior.

O quadro de referência estabelece os domínios de avaliação, sendo a metodologia adotada e a escala de classificação igualmente importantes neste processo que resulta na elaboração de um relatório para cada escola, publicado na página da Inspeção Geral de Educação e Ciência (IGEC), organismo do Ministério da Educação e Ciência (MEC). O quadro de referência do primeiro ciclo avaliativo da AEE, especificamente no domínio Prestação do Serviço Educativo, incluiu os seguintes fatores: articulação e sequencialidade, acompanhamento da prática letiva em sala de aula, diferenciação e apoios, abrangência do currículo e valorização dos saberes e da aprendizagem. Assim sendo, em face do quadro de referência acima citado, neste primeiro ciclo avaliativo (2006-2011) é de referir que o domínio Prestação do Serviço Educativo e o fator Diferenciação e apoios foram objeto de classificação. Importa destacar que no primeiro ciclo e apoios obteve classificaçóes entre Muito Bom e Bom em 
maior percentagem, constando igualmente entre os pontos fortes, com maior frequência do que entre os pontos fracos das escolas (INSPEÇÃO GERAL DE EDUCAÇÃO, 20062011). No entanto, no segundo ciclo avaliativo (2011-2012) este fator desaparece e surge como referente nos campos de análise Práticas de ensino e Monitorização e avaliação do ensino e das aprendizagens. Acresce que neste ciclo avaliativo só foi atribuída classificação ao domínio Prestação do Serviço Educativo, não sendo objeto de classificação os campos de análise em questão (BIDARRA et. al., 2014).

Nesse contexto, foi nosso objetivo perceber como as práticas de diferenciação e apoios têm sido reportadas à luz da AEE, procurando mapear estas mesmas práticas, tomando como base os relatórios do segundo ciclo avaliativo (iniciado em 2011, relativos à Zona Centro de Portugal Continental) e analisando e discutindo os dados obtidos, confrontando-os com a legislação atual e a avaliação das medidas educativas da educação especial, na sequência de outra intervenção da Inspeção Geral de Educação e Ciência que tem como propósito dar conta destas mesmas práticas (INSPEÇÃO GERAL DE EDUCAÇÃO, 2011-2012).

\section{Metodologia}

Para este estudo de natureza documental fizemos uso de 42 relatórios da AEE do 2o Ciclo avaliativo (20112012), referentes às escolas públicas da Zona Centro de Portugal Continental. Neste viés, utilizamos a técnica análise de conteúdo que nos permite desvendar sistematicamente o conteúdo manifesto nas mensagens (AMADO, 2009). Com efeito, foi nosso objetivo perceber como as práticas de diferenciação e apoios têm sido caracterizadas e mapeadas à luz da AEE, tomando como base o conteúdo presente nos relatórios do $2^{\circ}$ Ciclo avaliativo, acima citado.

A análise incidiu no domínio Prestação do Serviço Educativo, considerando como categorias os campos de análise expressos no quadro de referência e como subcategorias

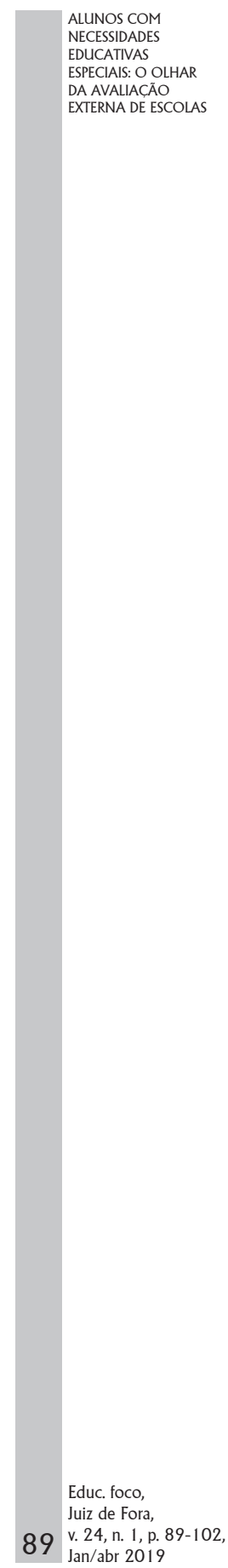


os referentes do referido domínio. Analisaram-se ainda os conteúdos relativos aos pontos fortes e áreas de melhoria das escolas. As categorias de análise estão expressas na matriz conceptual apresentada no Quadro 1:

\begin{tabular}{|c|c|}
\hline Categoria & Subcategoria \\
\hline \multirow{7}{*}{$\begin{array}{l}\text { Planeamento e } \\
\text { articulaçáo }\end{array}$} & A1 - Gestáo articulada do currículo \\
\hline & $\begin{array}{l}\text { A2 - Contextualização do currículo e abertura ao } \\
\text { meio }\end{array}$ \\
\hline & A3 - Projectos curriculares de turma \\
\hline & A4 - Contextualização do projecto educativo (PE) \\
\hline & $\begin{array}{l}\text { A5- Utilização da informação sobre o percurso } \\
\text { escolar dos alunos }\end{array}$ \\
\hline & A6 - Coerência entre ensino e avaliação \\
\hline & A7 - Trabalho cooperativo entre docentes \\
\hline \multirow{5}{*}{$\begin{array}{l}\text { B-Práticas de } \\
\text { ensino }\end{array}$} & $\begin{array}{l}\text { B1 - Adequação das atividades educativas e do en- } \\
\text { sino às capacidades e aos ritmos de aprendizagem } \\
\text { das crianças e dos alunos }\end{array}$ \\
\hline & $\begin{array}{l}\text { B2 - Adequação das respostas educativas às crian- } \\
\text { ças e aos alunos com necessidades educativas es- } \\
\text { peciais }\end{array}$ \\
\hline & $\begin{array}{l}\text { B3 - Metodologia ativas e experimentais no ensi- } \\
\text { no e nas aprendizagens }\end{array}$ \\
\hline & $\begin{array}{l}\text { B4 - Rendibilização dos recursos educativos e do } \\
\text { tempo dedicado às aprendizagens }\end{array}$ \\
\hline & $\begin{array}{l}\text { B5 - Acompanhamento e supervisão da prática } \\
\text { letiva }\end{array}$ \\
\hline \multirow{6}{*}{$\begin{array}{l}\text { C-Monitoriza- } \\
\text { ção e avaliação } \\
\text { do ensino e } \\
\text { das aprendiza- } \\
\text { gens }\end{array}$} & C1 - Diversificação das formas de avaliação \\
\hline & $\begin{array}{l}\text { C2 - Aferição dos critérios e dos instrumentos de } \\
\text { avaliação }\end{array}$ \\
\hline & C3 - Avaliação dos programas individuais \\
\hline & $\begin{array}{l}\text { C4 - Monitorização interna do desenvolvimento } \\
\text { do currículo }\end{array}$ \\
\hline & $\begin{array}{l}\text { C5 - Eficácia das medidas de promoção do suces- } \\
\text { so escolar }\end{array}$ \\
\hline & C6- Prevenção da desistência e do abandono \\
\hline
\end{tabular}




\begin{tabular}{|l|l|}
\hline \multirow{4}{*}{$\begin{array}{l}\text { D- Pontos } \\
\text { fortes }\end{array}$} & D1 - Diversificação das formas de avaliação \\
\cline { 2 - 2 } & $\begin{array}{l}\text { D2 - Adequação dos apoios às crianças e aos alu- } \\
\text { nos com necessidades educativas especiais }\end{array}$ \\
\cline { 2 - 2 } & D3 - Prevenção da desistência e do abandono \\
\hline \multirow{2}{*}{$\begin{array}{l}\text { E- Áreas de } \\
\text { melhoria }\end{array}$} & E1 - Eficácia das medidas de apoio educativo \\
\cline { 2 - 2 } & $\begin{array}{l}\text { E2 - Adequação dos apoios às crianças e aos alu- } \\
\text { nos com necessidades educativas especiais }\end{array}$ \\
\hline
\end{tabular}

Quadro 1 - Matriz conceptual para análise de conteúdo

Em seguida, após a construção da matriz conceptual, procedemos à análise das frequências dos indicadores específicos das práticas de Diferenciação e Apoios, bem como nas categorias em destaque.

\section{Resultados}

A análise das práticas de diferenciação e apoios no âmbito dos relatórios da avaliação institucional de escolas mostrou-nos um maior número de referências a essas práticas no campo de análise B-Práticas de Ensino, comparativamente à sua referência nos campos de análise A-Planeamento $e$ Articulação e C-Monitorização da Avaliação do Ensino e das Aprendizagens. Revelou-nos ainda um maior número de referência das práticas de diferenciação e apoios nos Pontos fortes comparativamente às Áreas de melhoria das escolas (cf. Figura 1).

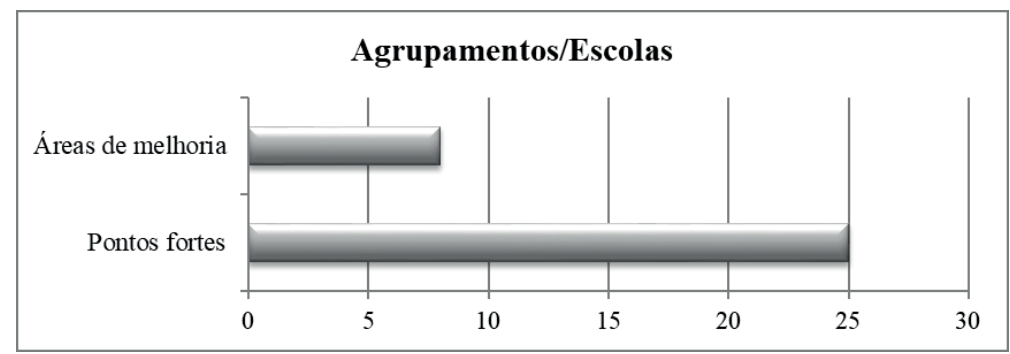

Figura 1: Frequência dos pontos fortes e áreas de melhoria nos agrupamentos de escolas e nas escolas 
Este resultado pode ser interpretado pelo fato de Maria da Graça Amaro BIDARRA na categoria $B$ - Práticas de ensino estarem presentes as subcategorias B1-adequaçáo das atividades educativas e do ensino às capacidades de ritmos de aprendizagens das crianças e dos alunos e B2- adequaçóes das respostas educativas às crianças e alunos com NEE. Relativamente aos indicadores das práticas de diferenciação e apoios nos Pontos fortes e Áreas de melhoria da escola, registou-se uma maior frequência nos primeiros, o que vai ao encontro das classificaçóes elevadas obtidas neste fator no primeiro ciclo avaliativo. Sobre os indicadores específicos das práticas de Diferenciaçáo e Apoios obtivemos os seguintes resultados.

Nas categorias A-Planeamento e articulação e CMonitorização e avaliação do ensino e das aprendizagens, há uma menor frequência em indicadores das práticas de diferenciação e apoios o que nos indica que estas práticas têm sido menos alvo planeamento e de avaliação, não estando tão presentes nos documentos estruturantes da escola, resultado que está de acordo com o referido nos relatórios da IGEC sobre as medidas de Educação Especial, que consideram os referidos aspetos como um aspeto a melhorar (INSPEÇÃO GERAL DE EDUCAÇÃO, 2011-2012).

As medidas de apoio mais referidas são o Programa Educativo Individual (PEI) e o Currículo Específico Individual (CEI), encontrando-se em número mais reduzido o Programa Individual de Transição (PIT) (cf. Figura 2). Com efeito, consideramos que a referência a estas medidas educativas cumpre com o que está legislado pelo Decreto-Lei 3/2008, de 7 de janeiro onde faz menção às mesmas e está de acordo com a posição de diferentes autores que sublinham que a inclusão supóe a sua relação com a educação especial (CORREIA, 2010). 


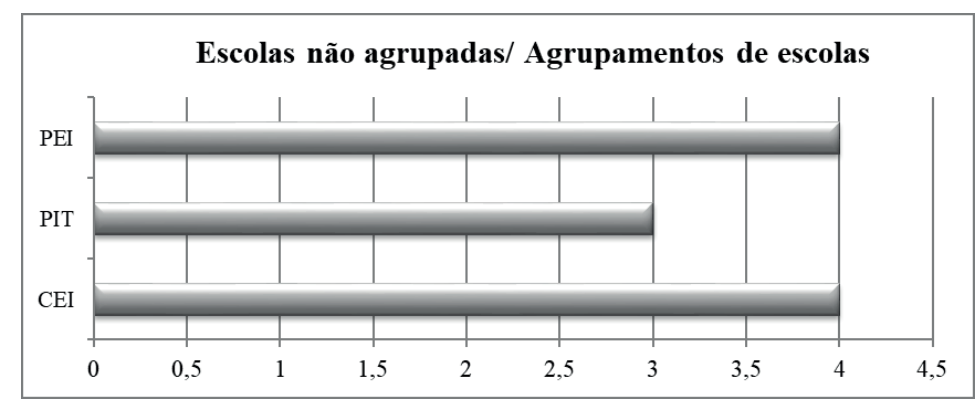

Figura 2: Frequência das medidas educativas na Educação Especial

Quanto às estruturas organizativas da Educaçáo Especial registou-se maior frequência de Unidades de Ensino Estruturado em relaçáo às Unidade de Multideficiência e Escolas de Referência (cf. Figura 3). Estas estruturas organizativas são igualmente referidas na categoria $D$ - Pontos fortes das escolas.

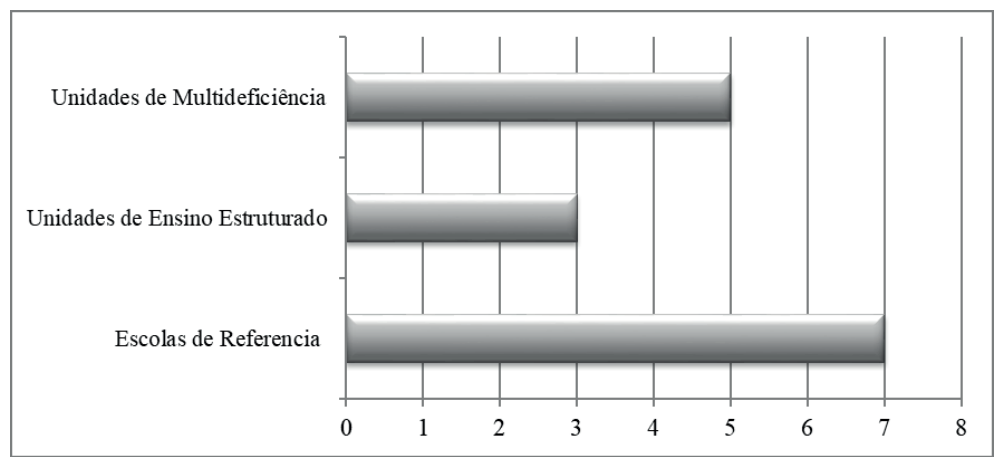

Figura 3: Estruturas organizativas da Educação Especial

No que se refere aos indicadores das práticas de diferenciação e apoios nos campos de análise estão presentes as frequências em cada categoria de análise (cf. Figura 4, Figura 5, Figura 6, Figura 7, Figura 8). 


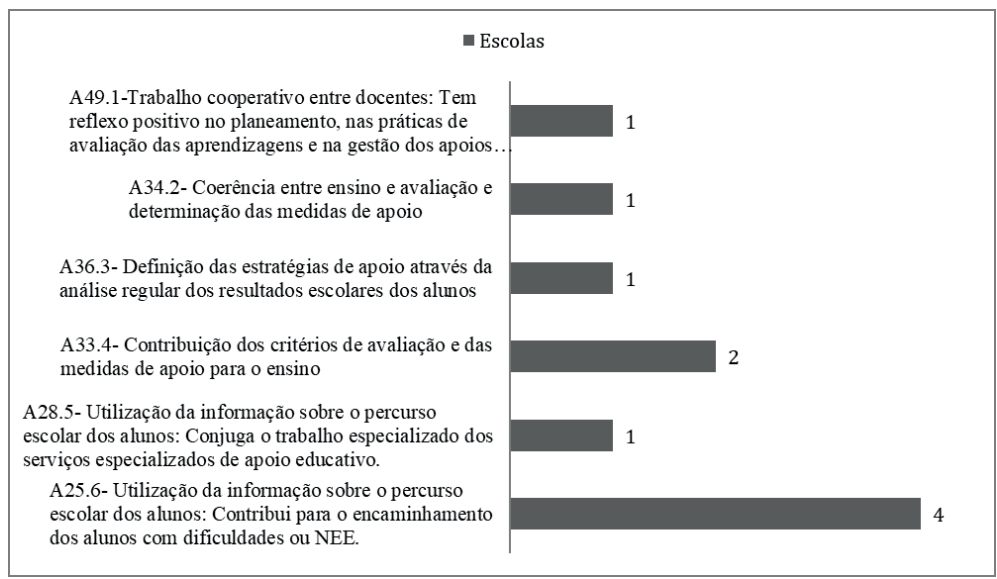

Figura 4: Indicadores presentes nas subcategorias da categoria APlaneamento e articulação

Como o exposto, os indicadores das práticas de Diferenciação e Apoios que apresentam maior frequência são A4 e A6. Sobre o primeiro converge com o que está legislado no Decreto-Lei $3 / 2008$ presente no artigo $13^{\circ}$ que faz menção à coordenação e aperfeiçoamento do PEI. Capucha (2009, p. 28) afirma que nas reunióes de avaliação nas escolas "permite obter dados essenciais para se monitorizar a eficácia das medidas educativas, podendo, a qualquer momento, ser necessário introduzir alteraçóes às medidas inicialmente definidas”. Sobre o segundo vai ao encontro do que está presente neste mesmo Decreto- Lei no que concerne ao documento PEI. Este, segundo o mesmo autor, bem como com o Decretolei 319/91 de 23 de janeiro, refere que o estabelecimento de ensino através da informação do percurso escolar do aluno pode direcioná-lo (em particular o com NEE), as medidas de apoio necessárias para o seu desenvolvimento no processo de ensino-aprendizagem.

$\mathrm{Na}$ categoria B- Práticas de ensino estão presentes os indicadores das práticas de diferenciação e apoios (cf. Figura 5) da qual pode-se verificar a frequência dos mesmos na Figura 5. 


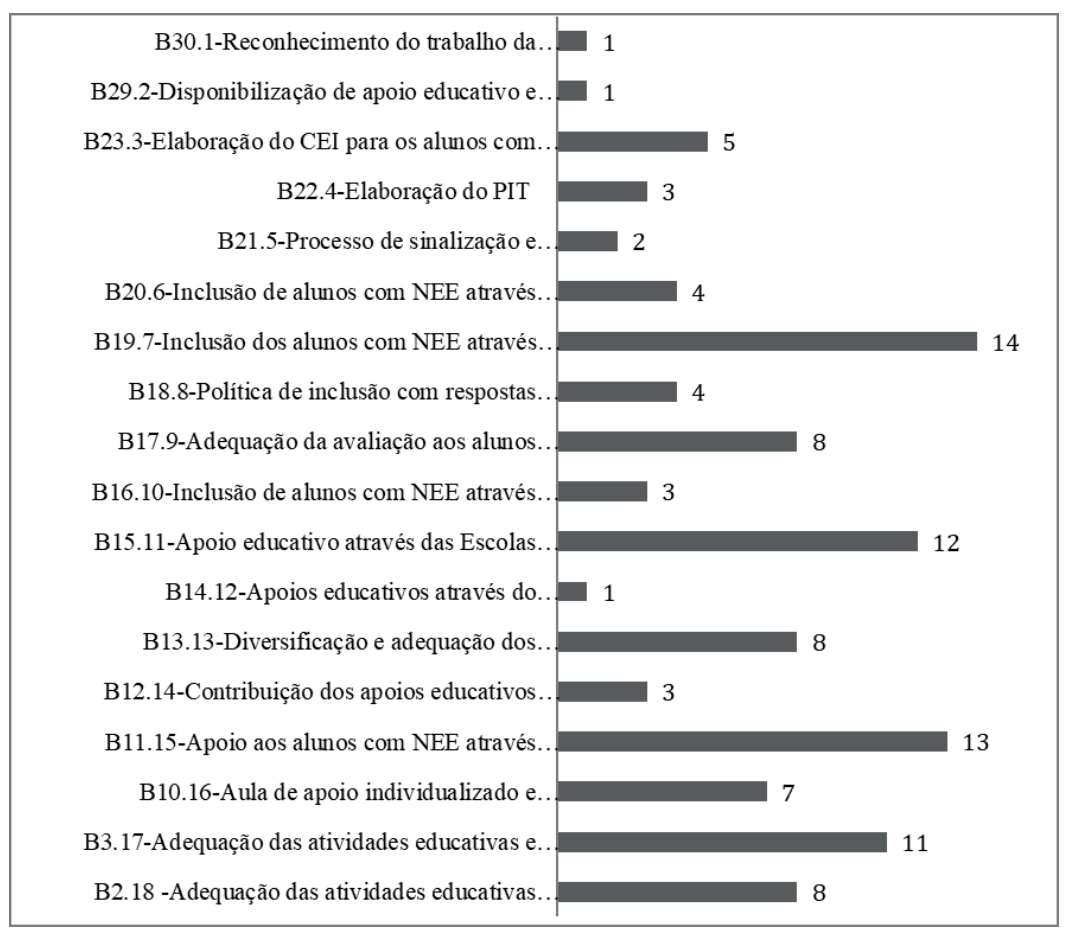

Figura 5: Indicadores presentes nas subcategorias da categoria B-Práticas de Ensino

Uma análise da figura 5 (cf. Figura 5) demonstra que os indicadores que apresentam frequência mais elevada são: B7, B9, B11, B13, B15, B16, B17, B18. Os indicadores B7, B16, B17, B18 estão de acordo com o Decreto-lei 3/2008, destacando o art. $16^{\circ}$ que refere a adequação do processo de ensino e aprendizagem. Conforme o autor Capucha (2008, p. 33) afirma esta adequação

(...) pressupóe uma abordagem assente nos princípios da diferenciação e da flexibilização ao nível do currículo: (i) áreas curriculares e disciplinas; (ii) objectivos e competências; (iii) conteúdos; (iv) metodologias; (v) modalidades de avaliação, bem como dos elementos de acesso ao currículo como sejam, entre outros, a organização e gestão do espaço, do tempo, dos recursos humanos, materiais e financeiros. 
Sobre o indicador B9, está de acordo com o art. $20^{\circ}$ Maria da Graça Amaro BIDARRA do mesmo decreto que refere as adequaçóes no processo de avaliação. No que concerne ao indicador B11, este também está de acordo com o decreto em questão, no que se refere às modalidades específicas da Educação Especial, ou seja, as Escolas de Referência, Unidades de Multideficiência, Unidades de Ensino Estruturado.

Correia (2008, p. 13) refere que "A inclusão não deve ser a mera colocação de todos os alunos com NEEs nas classes regulares sem que um conjunto de pressupostos sejam assegurados (legislação, recursos, colaboração, etc.)".

$\mathrm{Na}$ categoria C- Monitorização e avaliação do ensino e das aprendizagens estão presentes os indicadores das práticas de diferenciação e apoios (cf. Figura 6) podendo-se verificar a frequência dos mesmos na Figura 6.

\begin{tabular}{|c|c|}
\hline $\begin{array}{l}\text { C32.1-Prevenção da desistência e.. } \\
\text { C31.2-Prevenção da desistência e.. } \\
\text { C29.3-Prevenção da desistência e.. } \\
\text { C24.4-Monitorização do percurso.. } \\
\text { C23.5-A monitorização dos.. } \\
\text { C22.6-A eficácia das medidas de.. } \\
\text { C18.7-Monitorização interna do.. } \\
\text { C5.8-Adaptação da avaliação por.. } \\
\text { C5.9-Adequação da avaliação à.. } \\
\text { C3.10-Avaliação diagnóstica por.. }\end{array}$ & 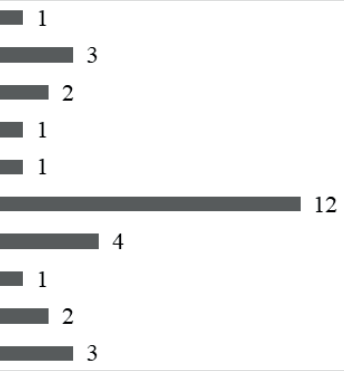 \\
\hline
\end{tabular}

Figura 6: Indicadores presentes nas subcategorias da categoria CMonitorização e avaliação do ensino e das aprendizagens

Sobre a figura 6 (cf. Figura 6), o indicador que apresenta frequência elevada é o C6- A eficácia das medidas de apoio educativo é avaliada. Sobre isto, o Decreto-lei 319/91 bem como o Decreto-Lei 3/2008, não fazem menção a este ponto. Entretanto, Capucha (2008) aponta que o Decreto-Lei 3/2008 refere que a adequação do processo de ensino-aprendizagem, que integra as medidas de apoio educativo "[...] vai exigir, por parte da escola, mudanças na sua organização de forma a encontrar e a desenvolver, para todos os alunos, as respostas educativas mais adequadas" (p. 33). 
Os resultados relativos à categoria $\mathrm{D}$ - Pontos fortes são apresentados na Figura 7.

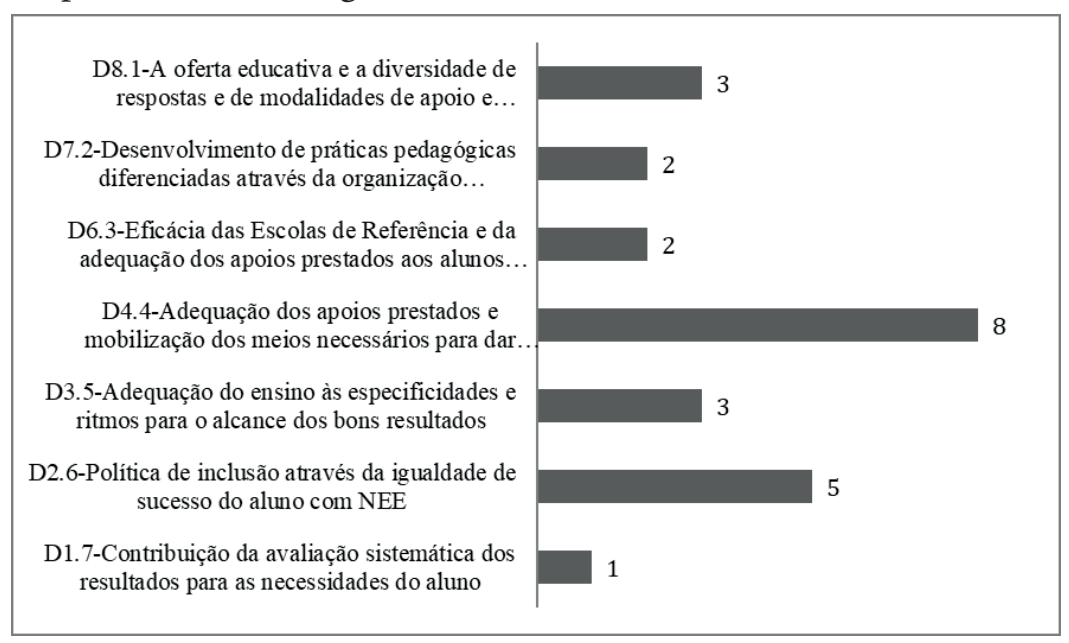

Figura 7: Indicadores presentes nas subcategorias da categoria D- Pontos Fortes

De acordo com os resultados obtidos (cf. Figura 7) os indicadores que apresentam frequência elevada são o $\mathrm{D} 4$ e D6. O primeiro integra o que está previsto nos decretos-lei 319/91 bem como no Decreto-lei 3/2008 no que se refere às medidas educativas associadas ao processo de ensino e de aprendizagem, fazendo menção, neste âmbito, ao apoio pedagógico personalizado aos alunos com NEE. No que se refere ao indicador D6, Leite (2011) afirma que a escola inclusiva precisa dar respostas condizentes ao progresso no processo de ensino e de aprendizagem de seus alunos. Niza (1996) reforça que o professor necessita valorizar a diferenciação no propósito de garantir o direito de acesso e igualdade de condiçóes educativas de qualidade a todos os alunos, permitindo o sucesso destes no processo de ensino e de aprendizagem. Ainda, o Decreto-lei 3/2008 no seu art. $1^{\circ}$ refere que a Educaçáo Especial tem por objetivo "[...]a inclusão educativa e social, o acesso e o sucesso educativo, a autonomia, a estabilidade emocional, assim como a promoção da igualdade de oportunidades [...]" (CAPUCHA, p. 15). 
E4.4-A rendibilização dos apoios disponibilizados aos alunos para a recuperação das dificuldades e na melhoria dos resultados E3.3-Práticas de diferenciação pedagógica para $o$ atendimento específico e sucesso pleno aos

E2.2-Avaliação dos tempos afetos a apoio e recuperação para os alunos

E1.1-Avaliação da eficácia dos programas individuais por referência da CIF aos alunos com NEE alunos com NEE

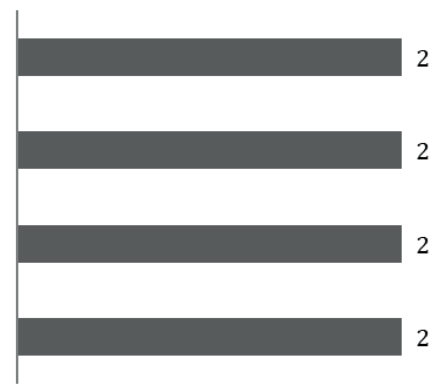

Figura 8: Indicadores presentes nas subcategorias da categoria E- Áreas de melhoria

Sobre a categoria E- Áreas de melhoria (cf. Figura 8), verifica-se que há equilíbrio na frequência dos indicadores. Este resultado, nos fornece dados para realização de futuros estudos de casos, tendo um olhar mais atento nesses indicadores. Também este dado, como pode-se verificar no indicador E4 presente nas Áreas de melhorias vai ao encontro dos primeiros resultados deste estudo (cf. Figuras 1) onde fez menção a baixa frequência das práticas de diferenciação e apoios nas categorias A-Planeamento e articulação e C-Monitorização e avaliação do ensino e das aprendizagens. Somando-se a isto, a avaliação é igualmente referida nos relatórios da modalidade da Educação Especial enquanto aspeto a melhorar.

\section{CONCLusóes}

Os resultados desse estudo revelam que as escolas da Zona Centro de Portugal Continental têm desenvolvido práticas de inclusão, reportadas nos relatórios de AEE, ainda que sejam menos referidas a planificação e a avaliação destas mesmas práticas, devendo assumir maior visibilidade nos documentos estruturantes, o que está de acordo com os relatórios da IGEC na modalidade da educação especial, que resultam de uma intervenção mais específica no que concerne às respostas educativas para alunos com NEE.
Com efeito, houve mais referência às práticas de diferenciação e apoios nas categorias B-Práticas de Ensino e 
D- Pontos fortes, comparativamente às demais categorias de análise. Acresce destacar que houve uma maior referência ao Programa Educativo Individual (PEI) e ao Currículo Específico Individual (CEI) comparativamente ao Programa Individual de Transição (PIT). Sobre as estruturas organizativas do ensino especial, surgem com maior frequência as Escolas de Referência comparativamente às Unidades de Multideficiência e às Escolas de Ensino Estruturado. Sublinhe-se que os indicadores das práticas de diferenciação e apoios presentes nas categorias vão ao encontro da legislação atual, no que se refere ao Decreto-Lei 3/2008.

Os dados presentes nos relatórios da AEE, no que se refere ao domínio Prestação do Serviço Educativo, possibilitaram ainda identificar as escolas que se têm destacado nas práticas de diferenciação e apoios, bem como as que necessitam melhorar neste âmbito, o que nos poderá conduzir em futuros estudos de caso. Com efeito, fica por conhecer a opinião e a atitude dos professores e outros elementos da comunidade educativa, cruzando diferentes olhares sobre as mesmas práticas o que auxiliará no desenvolvimento de projetos de intervenção e formação de professores, que constitui uma necessidade identificada em Portugal, de acordo com relatórios internacionais (TALIS, 2009-2010).

\section{REFERÊNCIAS}

\section{AMADO, J. Introduçáo à investigação qualitativa em} educaçáo. (Relatório de Provas de Agregação). Universidade de Coimbra, 2009.

BIDARRA, M. G. et.al.. Relatórios de avaliação externa: $\mathrm{Da}$ análise das redundâncias à ponderação diferencial dos resultados no primeiro ciclo de avaliaçáo. In J. A. Pacheco (Org.). Avaliaçáo Externa de Escolas. Quadro Teórico/ Concetual Porto. Porto Editora, 2014. (p. 229-246). ISBN: 978-972-0-34908-8 
CAPUCHA, L. Educação Especial. Manual de Apoio à Prática. Lisboa, 2008.

CORREIA, L. Alunos com necessidades educativas especiais nas classes regulares. Porto: Porto Editora, 1999.

CORREIA, L. Escola contemporânea e a inclusáo de alunos com NEE - Consideração para uma educação de sucesso. Porto: Porto Editora, 2008.

CORREIA, L. Educaçáo especial e inclusão - Quem disser que uma sobrevive sem a outra náo está no seu perfeito juízo. Porto: Porto Editora, 2010.

INSPEÇÃO GERAL DA EDUCAÇÃO. Avaliaçáo Externa das Escolas: Avaliar para a melhoria e confiança. Lisboa: Ministério da Educação - IGEC, 2006-2011. Disponível em: htp://www.ige.min-edu.pt. Acesso em 10/01/2014.

INSPEÇÃO GERAL DA EDUCAÇÃO E CIÊNCIA. Avaliaçáo Externa das Escolas, 2011-2012. Relatório. Lisboa: Ministério da Educação - IGEC, 2012. Disponível em: htp://www.ige.min-edu.pt. Acesso em 10/01/2014.

INSPEÇÃO GERAL DA EDUCAÇÃO. Educação Especial: Respostas Educativas 2011-2012. Lisboa: Ministério da Educação - IGEC, 2013. Disponível em: htp://www.ige.minedu.pt. Acesso em 08/05/2014.

LEITE, T. Currículo e necessidades educativas especiais. Aveiro: Universidade de Aveiro, 2011.

MARQUES, C. Inclusão e inovação: As atitudes dos professores do ensino regular no quadro da educação inclusiva, 2012. 198f. Dissertação de mestrado, Viseu: Universidade Católica Portuguesa.

MACANANEY, D. O contributo da CIF (versão para crianças e jovens) para a Educação Especial. In: CAPUCHA, 
L. Educaçáo Especial. Manual de Apoio à Prática. Lisboa, 2008.

NIZA, S. Necessidades especiais de educação: Da exclusão à inclusão na escola comum, 1996. Inovaçáo, 2, 139-149.

OLIVEIRA, R. Dos pressupostos da educaçáo inclusiva às medidas de diferenciaçáo e apoio e sua avaliaçáo, 2014. 114f. Dissertação de mestrado, Coimbra: Faculdade de Psicologia e Ciências da Educação de Coimbra.

RODRIGUES, D. Educaçáo e diferença: Valores e práticas para uma educação inclusiva. Porto: Porto Editora, 2001.

RODRIGUES, D. Perspectivas sobre a inclusão: Da educação à sociedade. Porto: Porto Editora, 2003.

Teaching and Learning International Survey (TALIS). Teachers' professional development an analysis of teacher's professional development based on the OECD's. Europear Union., 2009-2010.

\section{Legislaçáo consultada}

Lei no 319/91. Diário da República. Regulamenta a integração de alunos portadores de deficiência nas escolas. - I Série - No 193 de 23 de Agosto.

Decreto-Lei no 3/2008. Diário da República. Define a atuação dos apoios educativos, adequaçáo do processo educativo às necessidades educativas especiais, finalidades da inclusão de pessoas com NEE. - I Série - No 4 de 7 de Janeiro.

Portaria No 275- A/2012. Diário da República. Faz algumas adaptaçôes deste ultimo decreto face à regulação do atendimento dos alunos. 1. ${ }^{a}$ SERIE, No 176-Supl, de 11.09.201. 
